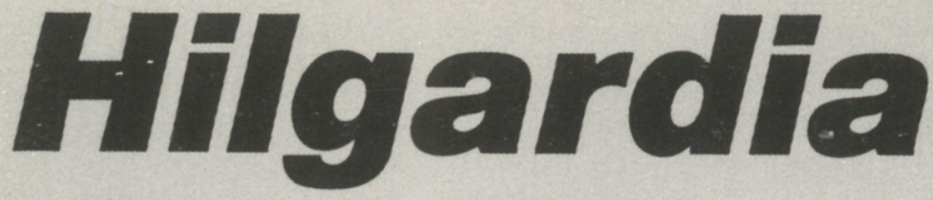

A. JOURNAL OF AGRICULTURAL SCIENCE PUBLISHED BY THE CALIFORNIA AGRICULTURAL EXPERIMENT STATION

Volume 57 - Number 3 - June 1989

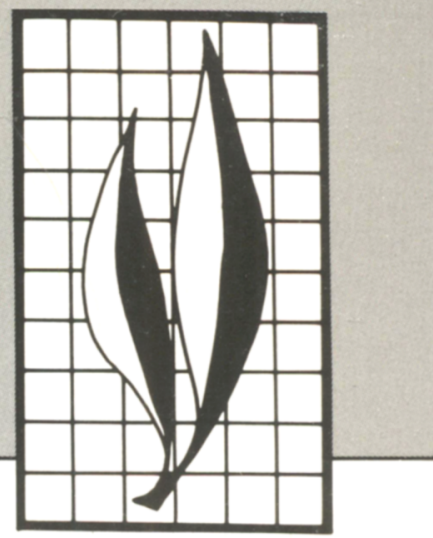

\title{
Spatial and Temporal Variability of Water- Soluble Organic Carbon in a Cropped Field
}

Dennis E. Rolston and Harvey J. Liss 


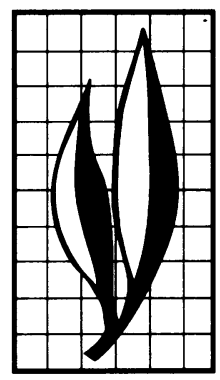

\section{ABSTRACT}

Little is known about the spatial and temporal variability of water-soluble organic carbon (WSC) within agricultural fields. The purpose of this research was to characterize the distribution, the mean, and the variance of WSC that occurs within a cropped field as a function of space and time. Freezing of soil samples showed no significant change in water-soluble organic carbon compared with that in fresh samples taken from a depth of $0.2 \mathrm{~m}$. Thus, water-soluble organic carbon was extracted from frozen soil samples taken from a 200-point grid established on a 1.2ha field, a 60-point grid within a 0.4-ha field, and a 55-point transect of a field amended with $45 \mathrm{Mg} / \mathrm{ha}$ of manure. The initial sampling was in the fall after the harvest of a sorghum crop.

The concentrations ranged from 23 to $274 \mathrm{mg} / \mathrm{kg}$ within the $1.2 \mathrm{ha}$ field. Over $90 \%$ of the concentrations were grouped around the mean of $39.8 \mathrm{mg} / \mathrm{kg}$. The higher values caused the distribution to be greatly skewed, such that a ln-normal distribution characterized the data better than a normal distribution. To be within $10 \%$ of the population mean at the $95 \%$ confidence level, 26 samples would be required if ln-normal distribution was assumed compared with 88 samples under normal distribution. Soil-water content was found to be well described by a normal distribution for the 200-point grid.

The means, variances, and frequency distributions of WSC changed dynamically throughout a 1-year period during which wheat and sorghum were grown. Mean WSC concentrations were highest in the spring and fall and lowest in the summer. The fall samplings had large variances and were best described by ln-normal frequency distributions, whereas other samplings during the year could be adequately described by normal distributions. The WSC concentrations showed only slight spatial dependency for samples taken $1.37 \mathrm{~m}$ apart and thus can be assumed

\section{THE AUTHORS:}

Dennis E. Rolston is Professor of Soil Science, Department of Land, Air and Water Resources, and Soil Physicist in the Experiment Station, University of California, Davis.

Harvey J. Liss, former Research Assistant, is presently Soil and Water Scientist, W. K. Kellogg Biological Station, Michigan State University, Hickory Corners, MI. 


\section{Spatial and Temporal Variability of Water- Soluble Organic Carbon in a Cropped Field ${ }^{1}$}

\section{INTRODUCTION}

Interest in water-soluble organic carbon (WSC) derives from three separate areas of investigation within soil science. It is well established that soluble organic matter forms stable combinations with metal ions (Stevenson and Ardakani 1972). Thus, considerable research has examined the role of soluble carbon with respect to the availability of micronutrients as well as its role in chemical weathering. Second, studies of nonpoint source pollution necessitate an estimation of the partitioning between soluble and particulate forms of $\mathrm{C}$ that enter surface runoff waters (Reddy, Khaleel, and Overcash 1980). Third, work has been done attempting to correlate WSC, an easily available energy form, to heterotrophic microbial processes.

Stanford, VanderPol, and Dzienia (1975) correlated "glucose equivalent" to denitrification. Burford and Bremner (1975) defined two fractions-WSC and the readily decomposable fraction-and examined their role in denitrification. There is a suggestion both implicitly and explicitly in work of this nature that an assessment of WSC can be used as an indicator of a soil's capacity to denitrify.

These studies have generally been conducted on a multitude of soils using duplicates or triplicates. The published data provide no indication of the variability occurring within the replicates or of the variability between the measured value and its distribution over a field. Before any of these parameters can have field applicability, information is needed on how the parameters are distributed over space and time, and how many samples would be required to characterize a given area. Few studies have examined WSC in the field for any extended period. Since WSC derives from several sources in the soil environment while serving as a microbial substrate, the amount found at any given time represents a balance between synthesis and destruction. Focht, Stolzy, and Meek (1979) studied the effect of varying irrigation management and organic amendments on denitrification in the field. They determined the soluble carbon in solution samples taken from five depths down to $2.3 \mathrm{~m}$. After sampling four times during one cropping season, they concluded that soluble $\mathrm{C}$ was normally distributed.

Meek et al. (1974) found significant movement of soluble organic $C$ to a depth of 0.8 $\mathrm{m}$ associated with high loading rates of manure and irrigation water. They concluded that manure application rates and irrigation schedules could be adjusted to create a reducing zone below the root zone by manipulating the movement of soluble carbon, thereby avoiding groundwater pollution by nitrate.

Air-drying of soil and subsequent rewetting and incubation have long been known to induce a burst of carbon dioxide production when compared with the same soil kept continuously moist. Lebedjantzev (1924) maintained this was caused by an increase in the solubility of organic substances. Stevenson (1956) verified the flush of respiration and observed a much higher concentration of amino acids in the air-dried soils. Birch and Friend (1956) attributed the flush of activity to an increase in rapidly decomposable material released from a protective association with clay minerals by the action of air-drying. Later Birch $(1958,1959)$ and Jager and Bruins (1975) maintained that drying increases the solubilization of organic matter. Patten, Bremner, and Blackmer

'Accepted for publication February 7, 1989. 
(1980) demonstrated that air-drying substantially increased a soil's ability to denitrify. They suggested that the effect of air drying was due to an increased quantity of readily utilizable organic matter but presented no data to this effect.

Thus, a number of researchers have postulated that air-drying increases the solubilization of organic matter, which becomes apparent upon the evolution of carbon dioxide with the subsequent rewetting. There is little evidence in the literature of the direct measurement of increased solubilization in the field as a result of air-drying.

Many researchers have maintained that drying causes significant changes in the physical, chemical, and microbial characteristics of a soil. Patten, Bremner, and Blackmer (1980) demonstrated that air-drying and storage in the air-dry state significantly alters a soil's capacity to denitrify. Although no data are presented on the status of WSC, they suggest that drying and storage affect "the quantity of organic matter readily utilized by denitrifiers." Given the number of samples required to examine the spatial distribution in a field, it was deemed necessary to establish the storage procedure that would least alter the samples when compared with the fresh condition. Therefore, we undertook a preliminary study comparing the WSC extracted from a fresh subsample, a frozen subsample, an air-dried subsample, and a ground and sieved air-dried subsample.

If WSC is assumed to be a good index of "available" carbon for some biological processes, it is important to more fully understand the variability of this parameter in a field at various times of the year. The objectives of this research were to determine if WSC is a dynamic parameter that varies over time and attempt to estimate the magnitude of that variation. Therefore, we established this experiment to determine the mean, the variance, and the distribution of this parameter with respect to space and time for an unamended and manure-amended field and to assess the change in WSC as a result of air-drying of the surface soil before and after irrigation of a cropped field.

\section{MATERIALS AND METHODS}

All studies were conducted on Yolo loam, which is a member of the fine, silty, mixed, nonacid, thermic, typic, Xerorthents family. For the storage study, 24 locations were chosen at random to afford a wide range of moisture contents and levels of soluble organic carbon. After thorough mixing, a subsample was immediately extracted and analyzed. Another subsample was frozen at $-10^{\circ} \mathrm{C}$ for 2 months, thawed, extracted, and analyzed. The remaining soil was air-dried at room temperature for 48 hours. A portion of the air-dried soil was ground and passed through a $0.2-\mathrm{mm}$ sieve. The WSC was subsequently determined on the air-dried soil.

The spatial study was conducted on a 1.2-ha field that had been uniformly cropped and managed for several years. Just before these experiments were initiated, from July to October, the field had been cropped to sorghum (Sorghum vulgare). After harvest, all standard vegetation was removed and the field was stubble-disced twice to a depth of $0.2 \mathrm{~m}$.

To study the spatial distribution over 1.2 ha, we established a 200 -point grid. The grid consisted of 20 rows and 10 columns. The rows and columns were each separated by $8.2 \mathrm{~m}$. The samples were taken in early November using an Oakfield sampler (24 $\mathrm{mm}$ I.D.) at the intersections of the rows and columns to a depth of $0.2 \mathrm{~m}$.

For the temporal study, we established two contiguous experimental fields of 0.4 ha within the same field we used for the spatial study. On one of the 0.4-ha fields, we established a grid consisting of 10 rows and 6 columns, each separated by $8.2 \mathrm{~m}$, and obtained samples at the intersections of the rows and columns to a depth of $0.2 \mathrm{~m}$. On the other 0.4-ha field, a transect of 55 points, spaced every $1.37 \mathrm{~m}$ was established across the field and sampled in early November to a depth of $0.2 \mathrm{~m}$. A quantity of cow manure mixed with straw bedding equivalent to $45 \mathrm{Mg} /$ ha was applied in mid-Novem- 
ber and incorporated to a depth of $0.2 \mathrm{~m}$. The manure contained approximately 15,000 $\mathrm{mg} / \mathrm{kg}$ WSC at a moisture content of $1.5 \mathrm{~g} / \mathrm{g}$.

Following the manure addition, the field was managed in exactly the same way as the contiguous unamended field, and both fields were planted to wheat (Triticum aestivum L.) in late November. After the wheat was harvested in May, the fields were planted to sorghum. The sorghum was furrow-irrigated four times (including a preirrigation); the last time was at the end of August. The unamended field was sampled as a grid, the amended field as a transect on all sampling dates.

Changes of WSC occurring during irrigation and subsequent drying periods were examined from July through September. A 10- by 2-m plot was established on a field that had been fallow for 2 years and planted to sorghum. Fertilizer was added at the rate of $300 \mathrm{~kg} \mathrm{~N} / \mathrm{ha}$ as $\mathrm{KNO}_{3}$. Irrigation water was applied with micro-sprinklers. Following a dry period of almost 2 months, the plot was irrigated three times during the experiment: June 29, July 19, and August 9. At each irrigation, $165 \mathrm{~mm}$ of water was applied.

Nine samplings were analyzed for WSC. The initial pre-irrigation sampling was taken at 28 randomly chosen sites. Subsequent sampling following the first and second irrigations was conducted at only 12 sites. In the third irrigation cycle, 16 sites were sampled. At every site, soil was removed from three depths: 0 to $0.05,0.05$ to 0.1 , and 0.1 to $0.3 \mathrm{~m}$.

All soil samples were sealed in polyethylene bags and stored at $-10^{\circ} \mathrm{C}$ until analyzed. With slight modifications, the extraction procedures outlined by Burford and Bremner (1975) were used to determine WSC. Soil samples were thawed 6 hours before extraction. After the soil was thoroughly mixed, $20 \mathrm{~mL}$ of double deionized water was added to duplicate $10-\mathrm{g}$ subsamples of each sample in a 50-mL polyethylene centrifuge tube. The subsample was gently shaken for 15 minutes and centrifuged at $11,000 \mathrm{rpm}$ for 7 minutes in a desktop centrifuge. The supernatant was decanted and centrifuged again for 1 hour at $11,000 \mathrm{rpm}$ in a refrigerated centrifuge at $5^{\circ} \mathrm{C}$. The clear remaining solution was filtered through a $0.45-\mu \mathrm{m}$ Millipore TF filter. The filtrate was analyzed on a total carbon analyzer. The filtrate of every subsample was analyzed twice for total carbon and twice for inorganic carbon. The reported WSC represents the average of the total carbon aliquots minus the average of the inorganic carbon aliquots adjusted to an oven-dry soil basis. Soil-water content was determined gravimetrically for all samples in duplicate.

\section{RESULTS AND DISCUSSION}

\section{Storage Pretreatments}

The means and standard deviations of the storage treatments are given in table 1 . The treatment means were compared using sequential analysis of variance and the Bonferroni test (Winer 1971). The standard deviations ranged from a low of $1.24 \mathrm{mg} / \mathrm{kg}$ for the frozen treatment to a high of $4.95 \mathrm{mg} / \mathrm{kg}$ for the air-dried treatment.

Table 1. MEANS AND STANDARD DEVIATIONS OF WATER-SOLUBLE CARBON CONCENTRATIONS (mg/kg) BETWEEN SUBSAMPLES FOR EACH PRETREATMENT

\begin{tabular}{lrc}
\hline \hline Treatment & Mean & Standard deviation \\
\hline Fresh & 42.9 & 1.49 \\
Frozen & 43.4 & 1.24 \\
Air-dried & 107.6 & 4.95 \\
Air-dried and ground & 143.4 & 2.38 \\
\hline
\end{tabular}


There was no significant difference at the 0.05 probability level between the samples immediately extracted (fresh) and those that were frozen and extracted. Significant differences existed, however, between all other combinations of storage treatments. Air-drying and grinding substantially increased the mean from that of the fresh or frozen samples. These results appear to be consistent with those of Patten, Bremner, and Blackmer (1980), who reported up to a two-fold increase in the denitrifying capacity of seven soils when air-dried. They attributed the increase in denitrification to the effect of air-drying on the quantity of organic matter readily utilized by denitrifiers. Similarly, Murayama and Moko (1975) found that grinding the soil increased the polysaccharide extracted with cold water by a factor of two to four. On this basis, we used freezing for storage of samples from the spatial and temporal studies.

\section{Spatial Distribution of Soluble Organic Carbon}

The data from the 200-point grid sampled in November ranged from a minimum of $23.8 \mathrm{mg} / \mathrm{kg}$ to a maximum of $274.2 \mathrm{mg} / \mathrm{kg}$. The average WSC of the two duplicates at each location are plotted as a histogram in figure 1 . It is evident that the bulk of the samples (greater than $90 \%$ of the sites) are grouped between 23.8 and $70 \mathrm{mg} / \mathrm{kg}$.

To further assess frequency distributions, we have prepared fractile diagrams for both WSC and the In of WSC (fig 2). The fractile diagram (Hald 1952; Biggar and Nielsen 1976) plots the cumulative distribution function of the normal distribution against the ranked parameter of interest. The fractile diagram of the soluble organic carbon for

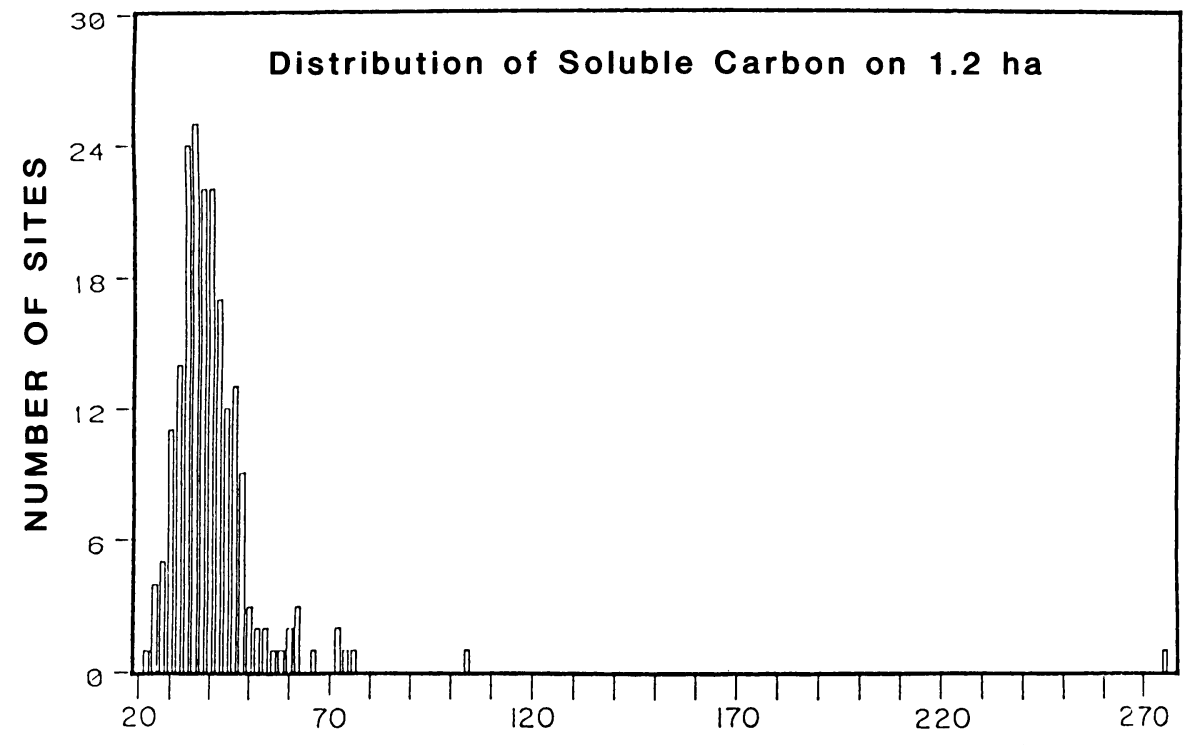

WATER SOLUBLE CARBON ( $\mathrm{mg} / \mathrm{kg})$

Fig. 1. Frequency distribution of the 200 samples of WSC from the 1.2-ha field. 

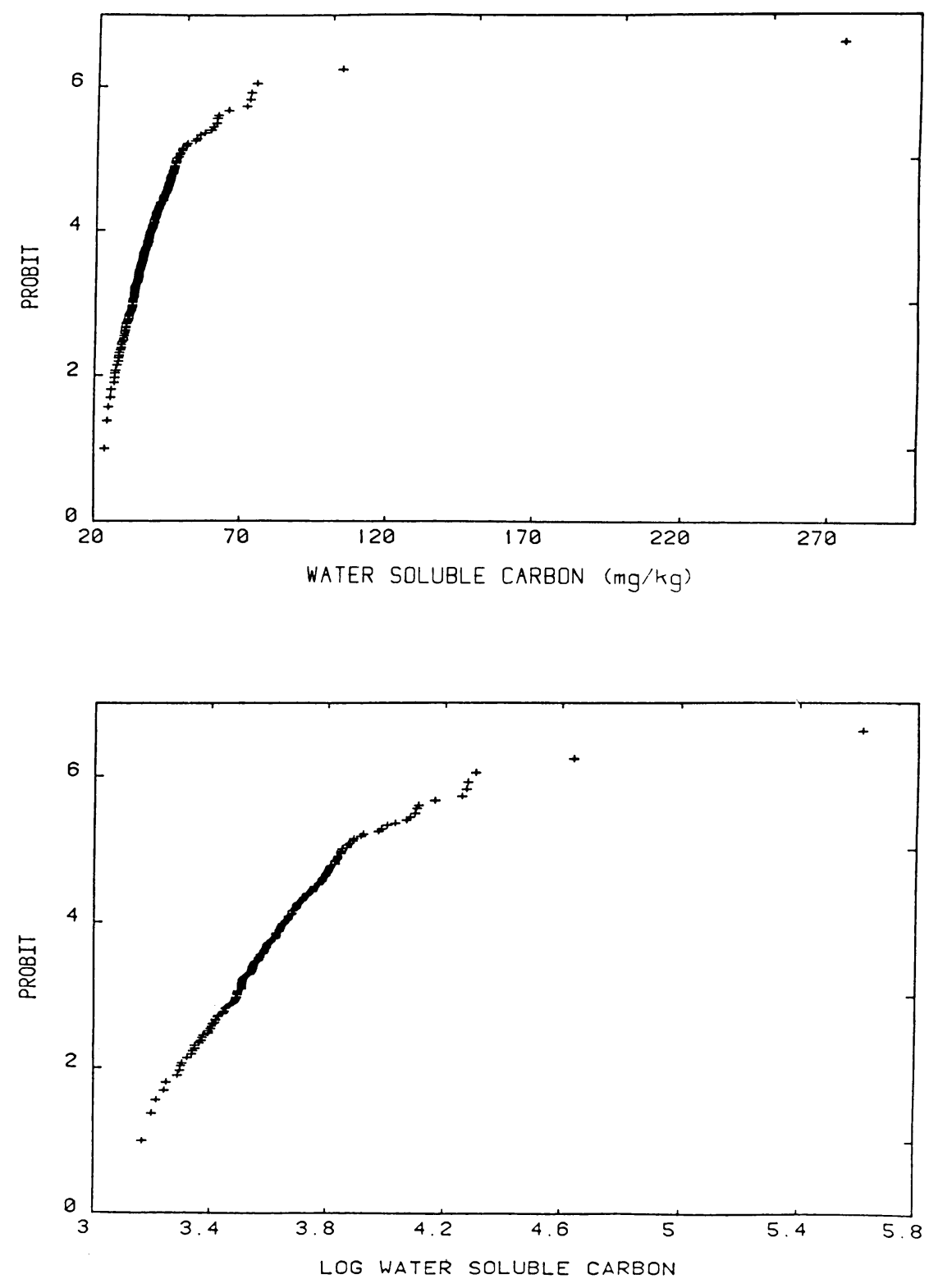

Fig. 2. Fractile diagrams of WSC and the natural logarithm of WSC. 
the 1.2-ha sampling shows that a normal distribution is approached for the concentrations below $50 \mathrm{mg} / \mathrm{kg}$, but the overall distribution cannot be described as normally distributed, since the higher values cause a wide departure from linearity. A regression analysis of the normal distribution versus the ranked concentrations yields a correlation coefficient of 0.61 . The fractile diagram of the cumulative distribution function for a normal distribution plotted against the natural logarithm of the ranked concentrations produces a better fit, with a correlation coefficient of 0.91 , but is still far from being linear. Removal of the one data point to the far right of the frequency distribution increases the correlation coefficients to 0.91 and 0.97 for the normal and $\ln$ normal distributions, respectively.

Thus, over the 1.2-ha field, the nonsymmetric distribution is better described by a lnnormal than a normal distribution. The ln-normal distribution, given its curvilinear nature, encompasses the higher values. Various statistical parameters of WSC for the 1.2-ha field (table 2) were calculated on the basis of a normal and ln normal distribution, and by the method suggested by Sichel (1966). By making the assumption of $\ln$ normality, the mean and the variance were calculated from $\bar{x}=\exp \left(\bar{y}+\hat{\sigma}^{2} / 2\right)$ and $\operatorname{Var}(x)=\bar{x}^{2}\left[\exp \left(\hat{\sigma}^{2}\right)-1\right]$ where $\bar{y}$ and $\hat{\sigma}^{2}$ are the sample arithmetic mean and variance of the ln-transformed variable, respectively. Attention should be given to the high values, since they cause the wide range, the high standard deviation, and the high coefficient of variation (47.7\%) if a normal distribution is assumed. The ln-normal and Sichel methods result in very similar values for the statistical parameters.

The areas of high concentration or "hot spots" (Parkin 1987) may have several causes. The hot spots may be due to sampling in a high concentration of plant residues, old root canals, macrofauna burrows, or mounds in the undulating surface drier than the surrounding area. Examination of pretreatments show that values of the magnitude causing the skewed distribution can arise from the air-drying process. However, a regression analysis attempting to correlate water content (0- to 0.2-m depth) to soluble carbon indicates no relationship. Similar analyses for the 0.4 -ha grids and the transects also indicate little or no correlation of WSC with soil-water content.

Autocorrelograms and variograms (Davis 1973) were also calculated for the watersoluble organic carbon data to ascertain if spatial dependence occurred for the sampling distances used in this study. Autocorrelograms and variograms, determined for the entire data set and for the data set with the largest outlier removed (Krige and Magri 1982), indicated no consistent spatial dependency. This means that samples taken 8.2 $\mathrm{m}$ or more from each other can be considered to be independent of sample location for this field site.

The advantage of recognizing that a ln-normal distribution characterizes the field data better than a normal distribution is seen in the lower number of samples required to attain a sample mean within $10 \%$ of the "population" mean. This was calculated from

$$
n=\left[\left(\mathrm{t}_{\alpha / 2} \sigma /(\bar{X}-\mu)\right]^{2}\right.
$$

where $\bar{X}$ is the sample mean, $\mu$ is the population mean, $\sigma$ is the standard deviation, $\alpha$ is the level of significance, and $t_{\alpha / 2}$ is the $t$ statistic (Hald 1952). Using this procedure whereby normal distribution is assumed, 88 samples would be required to be within $10 \%$ of the population mean at the $95 \%$ confidence interval. The number of samples to attain a sample mean within $10 \%$ of the "population" mean was also determined by assuming that the overall population was ln-normally distributed. Thus, by using the mean and standard deviation calculated from these equations and substituting into equation [1], it was found that only 26 samples would be required to be within $10 \%$ of the population mean at the $95 \%$ confidence level. To be within $10 \%$ of the mean, $\bar{y}$, of the In-transformed values would require only two samples. However, $10 \%$ of the In mean is about $40 \%$ of the untransformed mean, $\bar{x}$. 
Table 2. STATISTICAL PARAMETERS OF WSC (mg/kg) FROM THE 1.2-ha FIELD

\begin{tabular}{lccc}
\hline \hline Parameter & Normal & ln-normal & Sichel \\
\hline Mean & 40.3 & 39.9 & 39.8 \\
Variance & 372.8 & 109.3 & 109.2 \\
STD DEV & 19.3 & 10.5 & 10.4 \\
\% CV & 47.9 & 26.2 & 26.2 \\
Low 95\% CI & 38.1 & 38.7 & 38.4 \\
High 95\% CI & 42.6 & 41.1 & 41.6 \\
\hline
\end{tabular}

NOTE: The mean, etc., were calculated by assuming normal distribution and In normal distribution, and by using Sichel's method.

Although normal distribution did not fit the WSC concentrations particularly well, it does aptly describe the corresponding moisture contents of this sampling. A histogram of these values and a fractile diagram (not shown) indicated that water content was normally distributed. The mean of water content on an oven-dry weight basis for this sampling was 0.166 with a standard deviation of 0.019 . The coefficient of variation for the moisture content was $11.4 \%$ compared with $26.2 \%$ for the WSC.

\section{Temporal Changes in WSC Over One Year}

\section{Unamended}

Frequency distributions of the samplings of the 60-point unamended grid are given in figure 3. Fractile diagrams of the data from each sampling and the natural logarithm of that data were used to determine whether the distributions changed at different times of the year. The correlation coefficients of the regression analyses of the fractile diagrams show that, overall, the ln-normal distribution fits all of the samplings better than the normal distribution (table 3). Using the correlation coefficient as an indicator, the assumption of a ln-normal distribution appears to be a significant improvement only for the November, July, and October samplings. Removal of outliers results in better correlation coefficients for the normal and in some instances for the ln-normal cases but does not change the overall conclusion concerning improvements from using the ln-normal distribution.

Since Bartlett's test proved that the variances were unequal, a test of Independent Samples and Unequal Variances (Steel and Torrie 1980) was used to compare the means. The alpha level for the multiple comparison was established following procedures outlined by Winer (1971). The relevant statistics are summarized in table 4 . Means that are significantly different at the 0.05 probability level are followed by different letters in table 4 , where comparisons are made by assuming normal distribution for all samplings as well as by assuming normal distributions for the January, April, and August samplings and In-normal distributions for the November, July, and October samplings.

Assuming In-normal distribution for the July sampling does not alter any of the comparisons. The only important changes resulting from assuming ln-normal distribution are between the November sampling and the April, October, and August samplings, respectively. If the November sampling is assumed to be normally distributed, then there is no significant difference between the November sampling mean and those of the April, August, and October samplings. If the November sampling is more realistically assumed to be In-normally distributed, then the November sampling mean is significantly different from all three at the 0.05 probability level. 
Distribution of Soluble Carbon on 0.4 ha (Unamended)

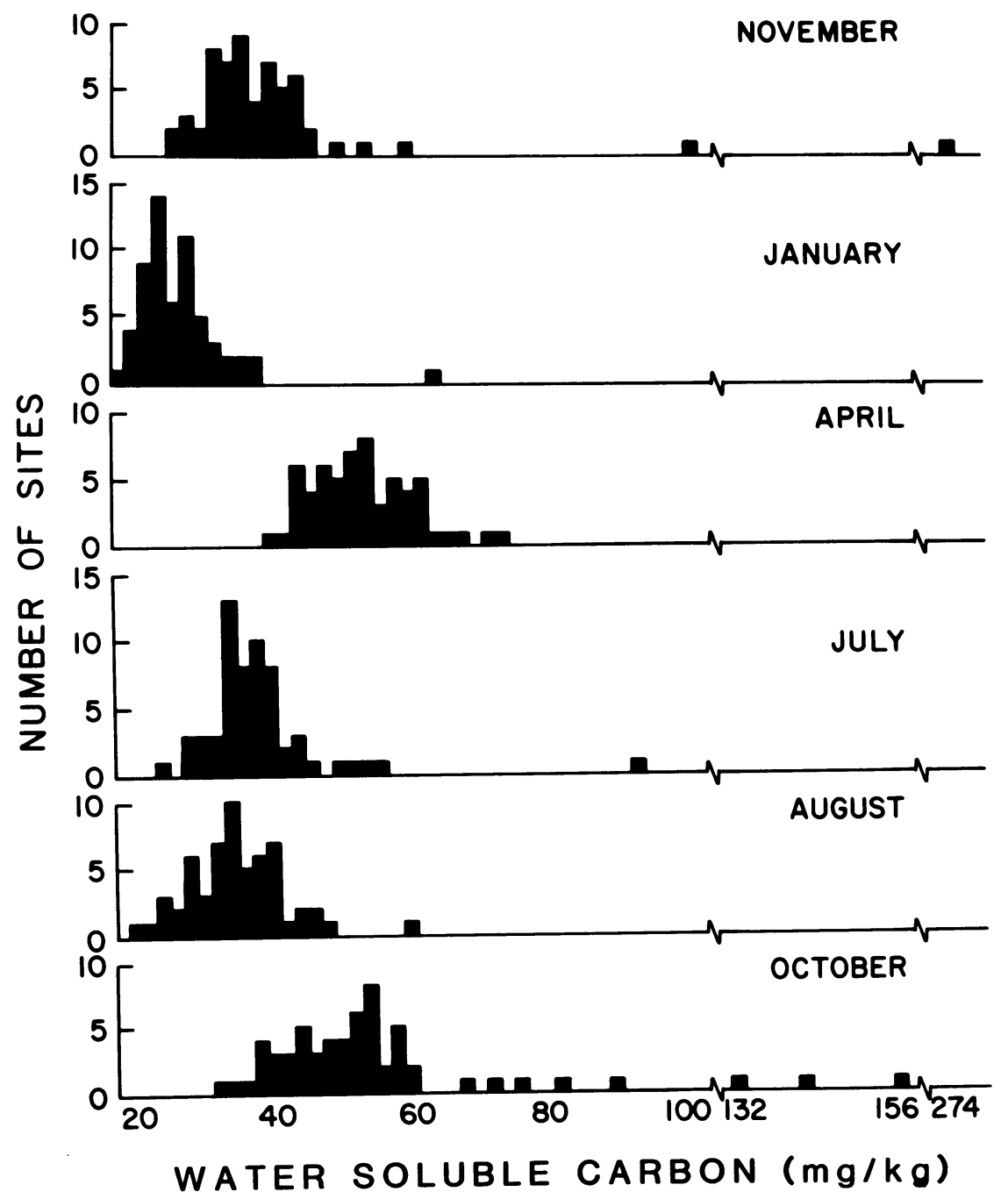

Fig. 3. Frequency distributions of the $60 \mathrm{WSC}$ samples from the 0.4 -ha, unamended field for six sampling times. 
Table 3. CORRELATION COEFFICIENTS OF FRACTILE DIAGRAMS FOR THE 0.4-ha, UNAMENDED FIELD AND MINIMUM NUMBER OF SAMPLES TO APPROXIMATE THE WSC MEAN WITHIN 10\% OF THE "POPULATION" MEAN

\begin{tabular}{|c|c|c|c|c|}
\hline \multirow[b]{2}{*}{ Sampling } & \multicolumn{2}{|c|}{ Correlation coefficient, $r$} & \multicolumn{2}{|c|}{ No. of samples } \\
\hline & Normal & In normal & Normal & In normal \\
\hline Nov. grid & .54 & .82 & 146 & 71 \\
\hline Jan. grid & .96 & .99 & 22 & 28 \\
\hline April grid & .99 & .99 & 5 & 12 \\
\hline July grid & .82 & .93 & 16 & 24 \\
\hline Aug. grid & .98 & .99 & 11 & 24 \\
\hline Oct. grid & .80 & .92 & 46 & 59 \\
\hline
\end{tabular}

Table 4. WATER-SOLUBLE ORGANIC CARBON STATISTICS FOR THE 0.4-ha GRID (60POINT) SAMPLINGS

\begin{tabular}{|c|c|c|c|c|c|c|c|}
\hline \multirow{2}{*}{$\begin{array}{l}\text { Sampling } \\
\text { date }\end{array}$} & \multirow[b]{2}{*}{ Status of field } & \multirow[b]{2}{*}{ Mean } & \multirow{2}{*}{$\begin{array}{c}\text { Standard } \\
\text { devia- } \\
\text { tion }\end{array}$} & \multirow{2}{*}{ Minimum } & \multirow[b]{2}{*}{ Maximum } & \multicolumn{2}{|c|}{$\begin{array}{l}\text { Significant } \\
\text { difference* }\end{array}$} \\
\hline & & & & & & Normal & ln-normal \\
\hline & & & & $\ldots m g / k g$ & & & \\
\hline November & Disced, no crop & 43.5 & 32.1 & 27.1 & 274.2 & $a b$ & $a^{\ominus}$ \\
\hline January & Wheat & 28.8 & 8.1 & 24.3 & 88.5 & $\mathrm{c}$ & $\mathrm{d}$ \\
\hline April & Wheat & 54.6 & 7.4 & 40.5 & 75.1 & $\mathrm{~b}$ & $\mathrm{~b}$ \\
\hline July & Sorghum & 39.1 & 9.5 & 25.0 & 95.2 & $\mathrm{a}$ & $\mathrm{ac}^{0}$ \\
\hline August & Sorghum & 36.0 & 7.2 & 21.4 & 60.0 & $\mathrm{a}$ & c \\
\hline October & Sorghum & 56.5 & 23.1 & 33.3 & 154.4 & b & $\mathrm{b}^{0}$ \\
\hline
\end{tabular}

* Rows followed by the same letter are not significantly different at the 0.05 level by test of Independent Samples and Unequal Variances (Steel and Torrie 1980).

- In-normal distribution assumed for November, July, and October.

It is evident from the above comparisons that the mean of WSC when extracted from a field soil sampled to a depth of $0.2 \mathrm{~m}$ changed as a function of the time of year. Following the harvest of sorghum in November, the mean was $43.5 \mathrm{mg} / \mathrm{kg}$, associated with a relatively large variance probably due to roots and incorporated plant material. From the January sampling through the spring and summer, the variance remained relatively low with minor fluctuations, only to substantially rise again just before harvest the following fall. In contrast to the variance, the means fluctuated considerably. The April mean $(54.6 \mathrm{mg} / \mathrm{kg})$ represented a $90 \%$ increase over the January value $(28.8$ $\mathrm{mg} / \mathrm{kg}$ ). This was followed by a substantial 30\% decrease with the sampling after the first irrigation in July $(39.1 \mathrm{mg} / \mathrm{kg})$ and a further decrease in August $(36.0 \mathrm{mg} / \mathrm{kg})$. Finally, the sampling just before harvest in October manifested a $74 \%$ increase to achieve the highest value for the year of $56.5 \mathrm{mg} / \mathrm{kg}$.

Simple correlations and Spearman-rank correlations were calculated for each of the 60 -point grids with all other sampling times. The results show that no correlation of the spatial pattern of WSC existed with time. Since soil samples for each sampling time were removed from locations as far as $1 \mathrm{~m}$ away from any other previous sampling location, these results imply that the variability from spot to spot within a small soil area was as large as that at some larger spatial scale, and temporal persistence of the spatial pattern was not apparent. Deletion of outliers reduced the general variance greatly for some sampling times but in general did not result in indication of any appreciable spatial dependence. 


\section{Manure amended}

Histograms of the 55 values for five sampling times with a class size of $2 \mathrm{mg} / \mathrm{kg}$ appear in figure 4. Fractile diagrams were also determined for each distribution. The correlation coefficients from the regression analysis of the fractile diagrams for the WSC concentrations and the natural logarithm of the ranked concentrations are given in table 5. It is clear that normal distribution fits the data fairly well, and, for that reason, normal distribution was assumed in comparing the means of the manure-amended transects. Some improvement in fit could be attained by deleting the two highest values from the January and October samplings.

Transects with samples taken closer than those of the grids were established to determine if any spatial dependence existed between the sites with respect to WSC. Not far from this field, on the same soil, the infiltration rate has been shown to be spatially dependent (Vieira, Nielsen, and Biggar 1981). Since the change in WSC may be related to downward transport, if spatial dependence could be shown, it could help to elucidate one of the processes causing change from one sampling time to another. We determined spatial dependence by constructing variograms and correlograms (Davis 1973). Some of the transects were autocorrelated at the first and second lags, while others had no autocorrelation. Deletion of one or two "outliers" from each sampling time did not significantly increase spatial dependence. However, if the data for all five sampling times are analyzed using a median polish (Tukey 1977) and the autocorrela-

\section{Distribution of Water Soluble Carbon 55 Site Transect (Amended)}
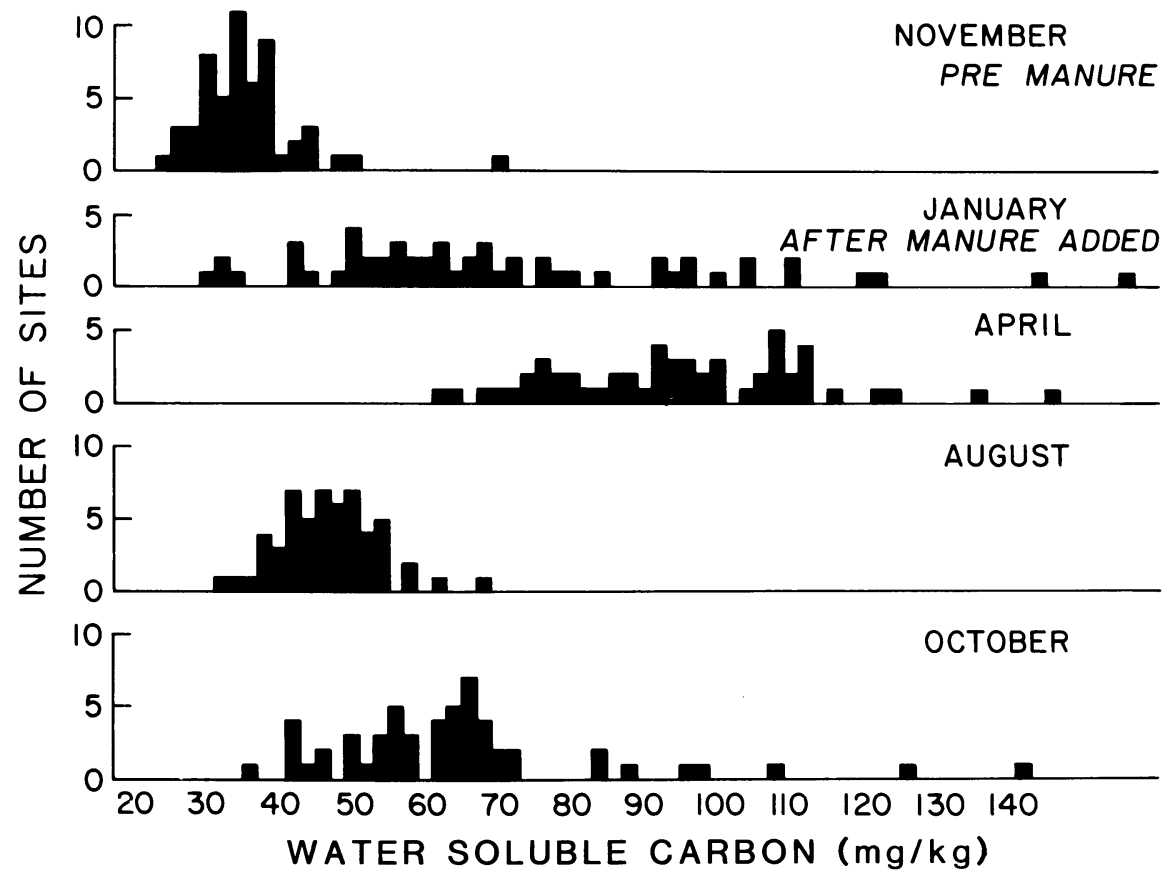

Fig. 4. Frequency distributions of the 55 samples from the transects of the manure-amended field for five sampling times. 
Table 5. CORRELATION COEFFICIENTS OF FRACTILE DIAGRAMS FOR MANURE-AMENDED TRANSECTS AND MINIMUM NUMBER OF SAMPLES TO APPROXIMATE THE WSC MEAN WITHIN 10\% OF THE "POPULATION" MEAN

\begin{tabular}{|c|c|c|c|c|}
\hline \multirow[b]{2}{*}{ Sampling } & \multicolumn{2}{|c|}{ Correlation coefficient, $\mathbf{r}$} & \multicolumn{2}{|c|}{ Number of samples } \\
\hline & Normal & Ln-normal & Normal & $\overline{\text { Ln }}$ \\
\hline November (premanure) & 0.91 & 0.97 & 11 & 20 \\
\hline January & 0.96 & 0.99 & 40 & 98 \\
\hline April & 0.99 & 0.99 & 10 & 20 \\
\hline August & 0.99 & 0.99 & 6 & 13 \\
\hline October & 0.91 & 0.97 & 24 & 43 \\
\hline
\end{tabular}

tion is conducted on the common spatial pattern for all five times, the data were significantly autocorrelated at a lag of $1(1.37 \mathrm{~m}$ ) (fig. 5). As with the unamended area, the spatial patterns of WSC were not significantly correlated in time. This again indicates that the local variability was as large as that at larger spatial scales.

Notwithstanding the assumption of normal distribution, the range of variances from 46.2 to 756.3 required that we use the test of Independent Samples and Unequal Variances (Steel and Torrie 1980). The only means that proved not to be significantly different from one another (table 6) was the comparison between the WSC sampled just after application of the manure in January $(71.8 \mathrm{mg} / \mathrm{kg})$ and the mean determined for the sampling just before the harvest in October $(65.9 \mathrm{mg} / \mathrm{kg})$.

The addition of the manure not only increased the mean but also drastically increased the standard deviation, from 7.2 before the manure addition to 27.5 after the addition (fig. 4, table 6). The spring sampling in April showed a reduction of the standard deviation to 17.7, and the August sampling a further reduction to 6.8. The sampling before harvest showed a substantial increase in the standard deviation to 19.7.

The mean obviously increased with the addition of the manure, from $36.2 \mathrm{mg} / \mathrm{kg}$ to $71.8 \mathrm{mg} / \mathrm{kg}$ (over 98\%). However, the spring sampling showed still a further increase of $34 \%$, raising the mean to $96.2 \mathrm{mg} / \mathrm{kg}$. At the sampling during the irrigated sorghum crop, the mean had dropped by $50 \%$ to $47.7 \mathrm{mg} / \mathrm{kg}$. The sampling before the October harvest showed an increase of $38 \%$ to $65.9 \mathrm{mg} / \mathrm{kg}$.

The data indicate significant changes in the mean and the variance of WSC during the year on both the amended and unamended field. The large variance observed in November before the manure additions was undoubtedly due to remnant roots and incorporated aerial portions of the previous crop that the discing had failed to disperse completely. The relatively low variance observed in the winter, spring, and summer on the unamended field probably resulted from the combined influence of water movement and crop growth. The manure addition, of course, caused an enormous perturbation of the system, but the same factors probably caused the reduction of the amended variance in the spring and then again in the summer.

Winter rains or irrigation may transport WSC deeper into the profile. The continually moist conditions cause $\mathrm{C}$ diffusion away from sites of higher concentrations. Thus, leaching and diffusion probably explain the significant reduction of the variance of the unamended field in January. These factors, together with the cool winter temperatures causing lowered microbial activity, resulted in a drop in the mean. Vigorously growing plants contribute WSC by root exudates, sloughed-off cells, and mucigel (Martin 1971; Rovira and Davey 1974). Extensive root proliferation would thus serve to reduce the overall variance and, combined with spring rains or summer irrigations, would maintain the low variance.

The near doubling of the unamended mean in April and the significant increase of the amended mean, notwithstanding the already high value after the manure addition, 


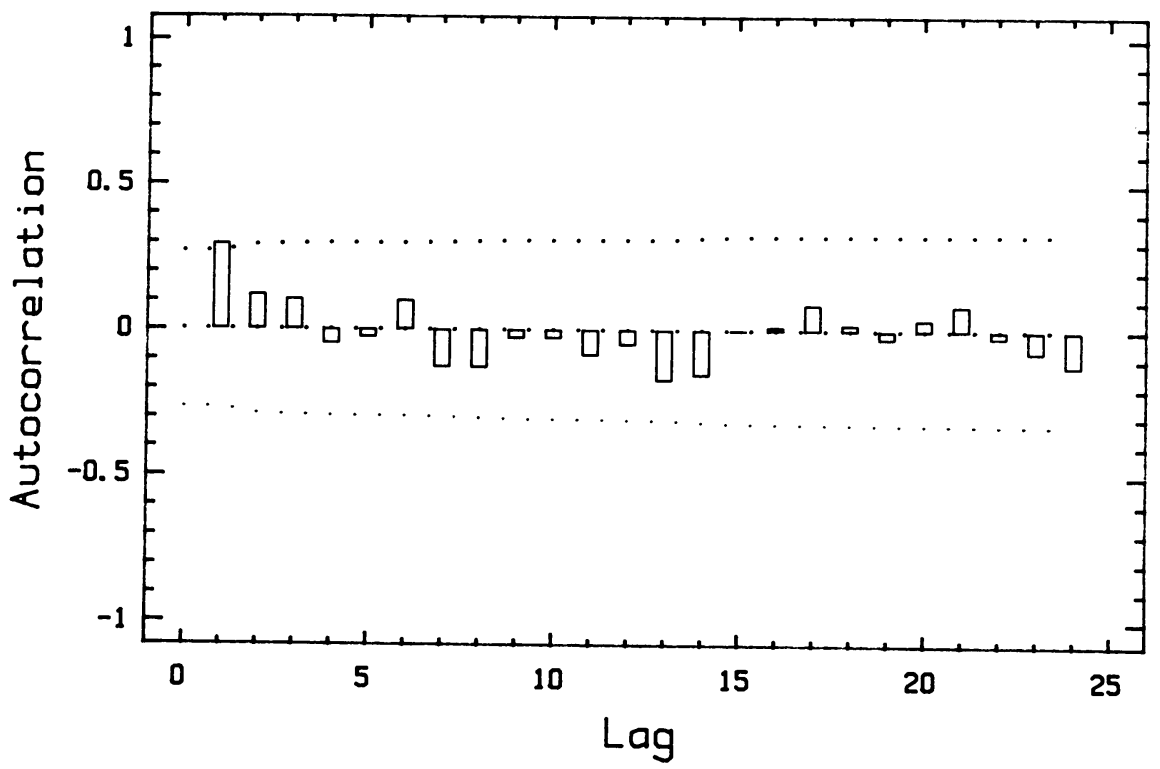

Fig. 5. Autocorrelogram of the common spatial pattern of WSC for all five sampling times. The common pattern was determined using median polish.

Table 6. WATER-SOLUBLE ORGANIC CARBON STATISTICS FOR MANURE-AMENDED TRANSECTS

\begin{tabular}{|c|c|c|c|c|c|c|c|}
\hline $\begin{array}{l}\text { Sampling } \\
\text { date }\end{array}$ & Status of field & Mean & $\begin{array}{c}\text { Standard } \\
\text { devia- } \\
\text { tion }\end{array}$ & Min. & Max. & $\begin{array}{c}\text { Coeffi- } \\
\text { cient of } \\
\text { variation }\end{array}$ & $\begin{array}{l}\text { Significant } \\
\text { differ- } \\
\text { erence }\end{array}$ \\
\hline \multirow{6}{*}{$\begin{array}{l}\text { November } \\
\text { (premanure) } \\
\text { January } \\
\text { April } \\
\text { August } \\
\text { October }\end{array}$} & & & ........mg/h & 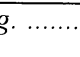 & $\ldots \ldots \ldots$ & & \\
\hline & disced, no crop & 36.2 & 7.2 & 24.9 & 71.0 & .20 & b \\
\hline & after manure, wheat & 71.8 & 27.5 & 31.2 & 146.3 & .38 & $\mathrm{a}$ \\
\hline & wheat & 96.2 & 17.7 & 62.0 & 148.0 & .18 & c \\
\hline & sorghum & 47.7 & 6.8 & 32.2 & 68.6 & .14 & d \\
\hline & $\begin{array}{l}\text { sorghum } \\
\text { (before harvest) }\end{array}$ & 65.9 & 19.7 & 36.0 & 1428 & 30 & a \\
\hline
\end{tabular}

* Means followed by the same letter are not significantly different.

probably resulted from several factors. The conditions favorable for plants would also induce an actively growing microbial population, which would utilize the readily available energy source but also increase the decomposition rate of the pre-existing soil organic matter. Also, soluble carbon has been shown to increase when soil is subjected to cold treatments. Although this soil was not exposed to extensive hours of freezing temperatures, any reduction in the microbial population would contribute to an increase in the WSC.

Given the widely reported flux of $\mathrm{CO}_{2}$ in response to wetting and drying (Birch 1959; Jager and Bruins 1975; Stevenson 1982) the summer months ought to show the greatest fluctuation in WSC observed during the year. The WSC should increase as the soil dries between irrigations. Each irrigation would then transport soluble carbon deeper within the profile while reactivating the resting microbial population. There may have 
been important increases of WSC during the drying cycle that were not identified by the two summer samplings presented here. The significantly lower means of WSC on the unamended field for the July sampling and then the further lowered means for the August sampling for an actively growing sorghum field must reflect the flushing action of the irrigations. The August mean of the amended plot is also the lowest mean observed there after the manure had been added. This explanation would seem to be corroborated in that the summer means on both fields are significantly lower than the October means for both amended and unamended fields. The crop in October grew less actively, but since the last irrigation was at the end of August, there was little flushing of previously released WSC.

The unamended grid was sampled at the same time as the manure-amended transects. There was no significant difference between the mean of the transect before the addition of manure and the mean of the unamended 0.4-ha grid. As expected, adding the manure to the transect significantly increased the mean of the transect 71.8 $\mathrm{mg} / \mathrm{kg}$ over the mean of the unamended grid $(28.8 \mathrm{mg} / \mathrm{kg})$, which actually decreased during the same period. Both means increased with the spring sampling and were still significantly different at the 0.05 probability level. Perhaps more importantly, the absolute increases were virtually identical, $25.8 \mathrm{mg} / \mathrm{kg}$ for the unamended grid and 24.4 $\mathrm{mg} / \mathrm{kg}$ for the manure transect. A comparison of the means at the August sampling shows a substantial decrease in the difference, but the means were still significantly different at the 0.05 level. Analysis of the unamended field sampled in October showed a greater increase (57\%) compared with 38\% for the manure transect. As with the April sampling, the increases were virtually the same in absolute terms, $19.2 \mathrm{mg} / \mathrm{kg}$ for the manure transect and $20.5 \mathrm{mg} / \mathrm{kg}$ for the unamended grid. The end result is that, by the October sampling, there was no longer a significant difference between the means of the two fields.

\section{Temporal Changes of WSC with Irrigation}

We analyzed the data on changes of WSC of the surface soil during irrigation, comparing three samplings within each of the three irrigation cycles. Each irrigation cycle thus consisted of three sampling dates: immediately before irrigation, immediately after irrigation, and 10 days after irrigation. The irrigations lasted 8 hours. Since previous results have shown that ln-normal distributions adequately described the WSC extracted from a cultivated sorghum field, the data were analyzed by analysis of variance for both untransformed and In-transformed data for each depth. In addition, a calculation was made that approximated a sampling over the whole $0.3 \mathrm{~m}$. Thus, the value of the sample from 0 to $0.05 \mathrm{~m}$ was added to the value from 0.05 to $0.1 \mathrm{~m}$. This sum was added to 4 times the value from 0.1 to $0.3 \mathrm{~m}$ and then divided by 6 to represent a weighted average.

Using ln-transformed data, it is apparent that significant change occurred in the 0to $0.05-\mathrm{m}$ soil depth as a result of irrigation, with time of sampling within the irrigation cycle accounting for a large degree of the differences between the means (table 7). The greatest significant difference due to the time of sampling was between the pre-irrigation sampling and the sampling immediately following the irrigation. These differences are well illustrated in table 7 and figure 6. WSC was high just before irrigation, decreased to its lowest point immediately after the irrigation, and then increased as the profile dried. In the third cycle, the mean followed that trend, although the differences were not as evident as in the previous two cycles.

Differences are also observable in the distribution of the data as manifested in the standard deviations. The standard deviation in the $0-$ to $0.05-\mathrm{m}$ depth ranged from a high of 70.9 in the first sampling of the first cycle to a low of 6.2 in the second sampling of the second cycle. 
Table 7. MEANS AND STANDARD DEVIATIONS ( $\mathrm{mg} / \mathrm{kg})$ FOR EACH SAMPLING OF THE 0TO 0.05-m SOIL DEPTH WITHIN EACH CYCLE

\begin{tabular}{ccccc}
\hline \hline Cycle, sampling & Sample size & Mean & Standard deviation & $\begin{array}{c}\text { Significant } \\
\text { difference }\end{array}$ \\
\hline 1,1 & 28 & 147.3 & 70.9 & $\mathrm{a}$ \\
1,2 & 12 & 48.9 & 8.5 & $\mathrm{~cd}$ \\
1,3 & 12 & 70.1 & 13.2 & $\mathrm{~b}$ \\
2,1 & 12 & 98.8 & 29.8 & $\mathrm{a}$ \\
2,2 & 12 & 32.7 & 6.2 & $\mathrm{e}$ \\
2,3 & 12 & 66.3 & 11.6 & $\mathrm{bc}$ \\
3,1 & 16 & 67.0 & 9.6 & $\mathrm{~b}$ \\
3,2 & 12 & 42.8 & 14.5 & $\mathrm{de}$ \\
3,3 & 12 & 48.2 & 14.3 & $\mathrm{~d}$ \\
\hline
\end{tabular}

* Means followed by the same letter are not significantly different at the 0.05 probability level.

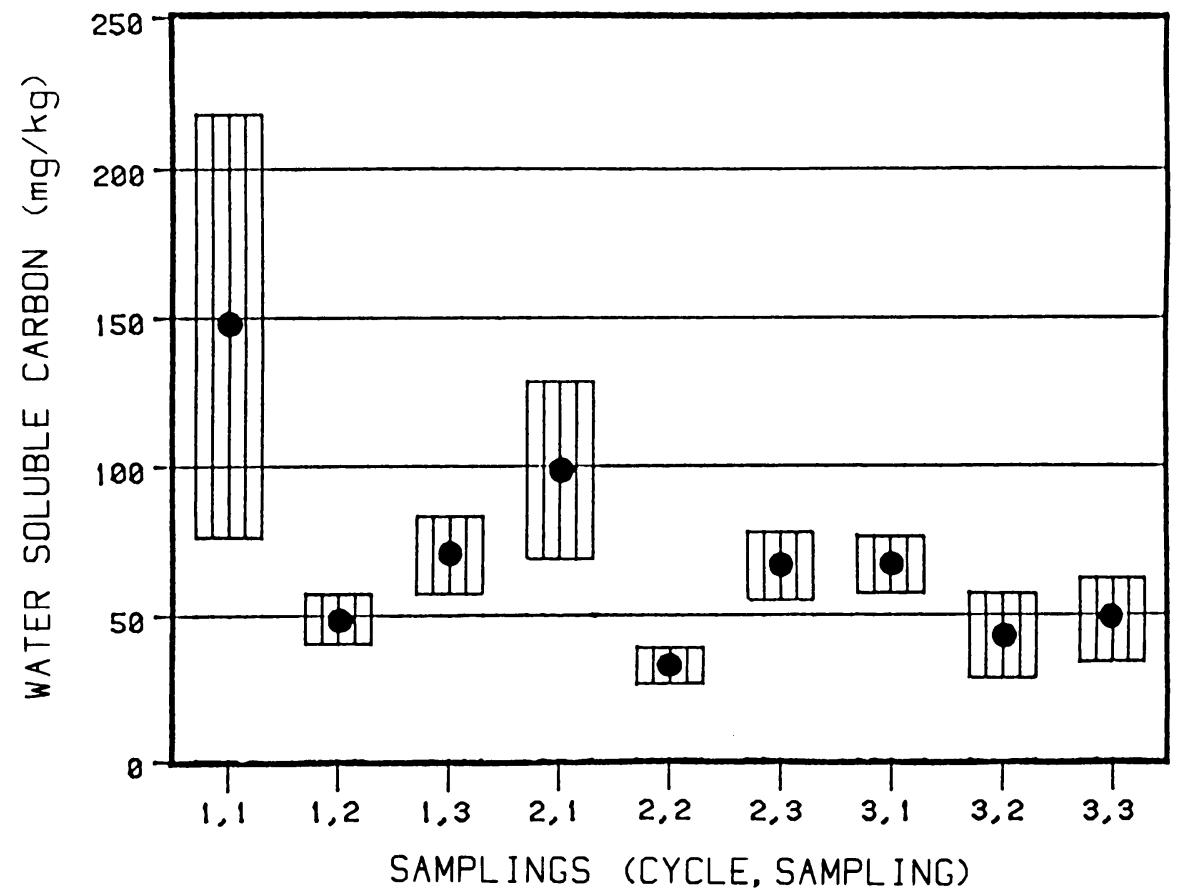

Fig. 6. Means and \pm one standard deviation of WSC from the 0 - to $0.05-\mathrm{m}$ depth for three irrigation cycles. Each mean was determined from at least 12 samples. 
The evidence is very strong that the $0.05-$ to $0.1-\mathrm{m}$ depth is a zone substantially different from the surface with respect to WSC. After the first pre-irrigation sampling, when the mean equalled $68.2 \mathrm{mg} / \mathrm{kg}$, there was only a $12-\mathrm{mg} / \mathrm{kg}$ difference between the lowest mean of $41.5 \mathrm{mg} / \mathrm{kg}$ during the third sampling of the first irrigation cycle and the highest mean of $53.1 \mathrm{mg} / \mathrm{kg}$ during the third sampling of the second irrigation cycle (fig. 7). Neither the ln-transformed nor the untransformed data indicate any significant difference between samplings within the cycle at this depth. The standard deviations are of the same order as those of the surface $(0-0.5 \mathrm{~m})$, ranging from a high of $38.7 \mathrm{mg} / \mathrm{kg}$ to a low of $5.3 \mathrm{mg} / \mathrm{kg}$.

By calculating the weighted average over the $0-$ to $0.3-\mathrm{m}$ depth of the values at each site (fig. 8), it is possible to ascertain whether composited sampling over the whole depth would mask differences. The analysis of variance does shows a significant effect at the 0.10 probability level, but the data are no longer strong enough to identify differences at the 0.05 level. The obvious trends in the 0 - to $0.05-\mathrm{m}$ depth are hardly apparent when the samples are composited.

The results for changes in WSC in the surface soil during irrigation demonstrate that changes in WSC are closely linked to the degree and duration of drying of the soil

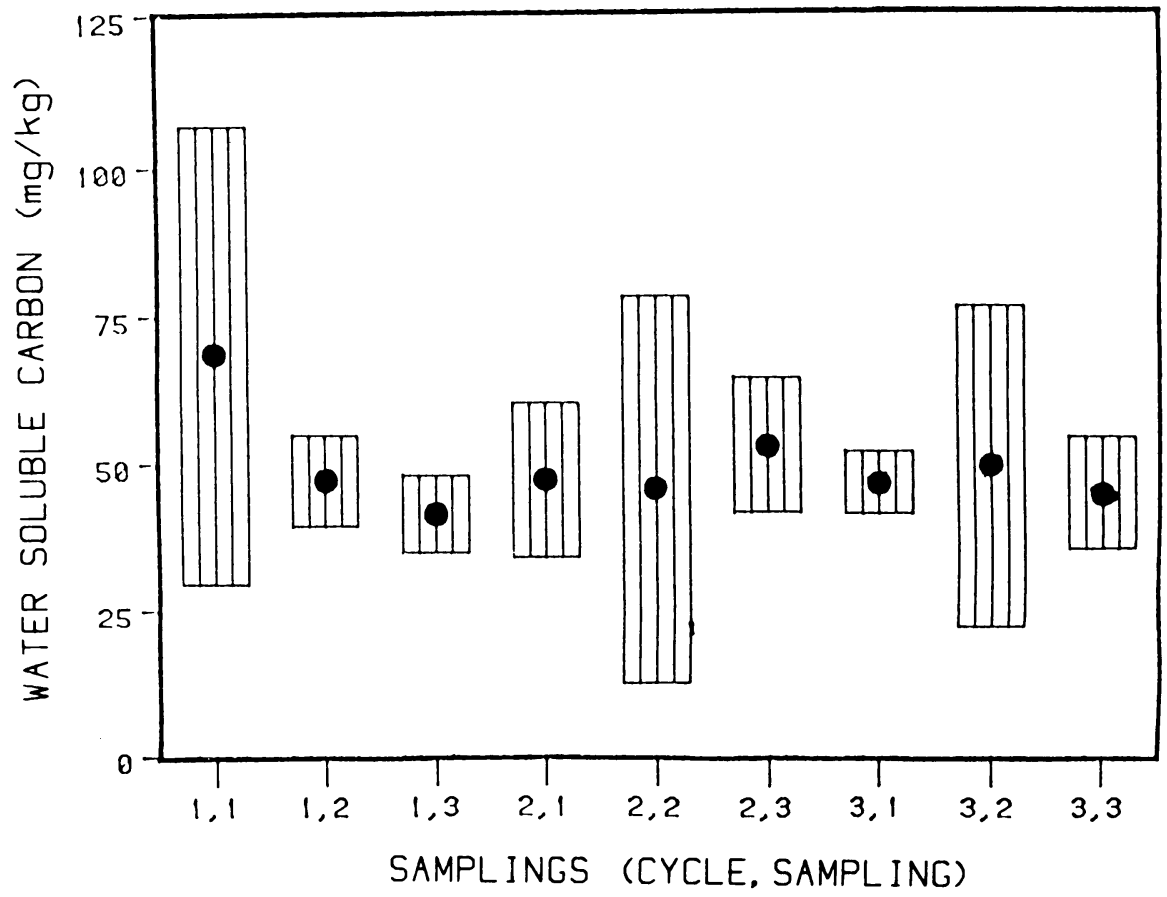

Fig. 7. Means and \pm one standard deviation of WSC from the $0.05-$ to $0.1-\mathrm{m}$ depth for three irrigation cycles. Each mean was determined from at least 12 samples. 
before extraction. Many researchers have postulated that these changes would occur in the field. For the most part, the only evidence offered of the increased solubilization was the related burst in carbon dioxide upon rewetting.

The highest level of WSC occurred in the upper $0.05 \mathrm{~m}$ of soil following a relatively long period of drying after the spring rains. The effect of irrigation was to drastically decrease the high level of WSC. In the period between irrigations, as the soil dried, a steady increase in WSC was observed. Notwithstanding the increase, the WSC concentrations never became as high as those preceding the first irrigation. Thus, there was a cyclic effect of increase and reduction, but the overall effect of irrigation was to dampen the amplitude of the increase.

Through the 10 weeks of sampling, there was little evidence of a plant contribution to soluble organic carbon. It is likely that, to detect a plant contribution, one would have to take samples from the rhizosphere, where plant deposition would primarily, if not exclusively, occur. Other researchers have maintained (Warembourg and Billes 1979) that all readily available carbon exuded into the rhizosphere is immediately transformed into high-molecular-weight microbial products.

A change observable in this experiment was the drastic decrease in WSC as a result of irrigation. The first irrigation, over a period of 8 hours, reduced the WSC by more

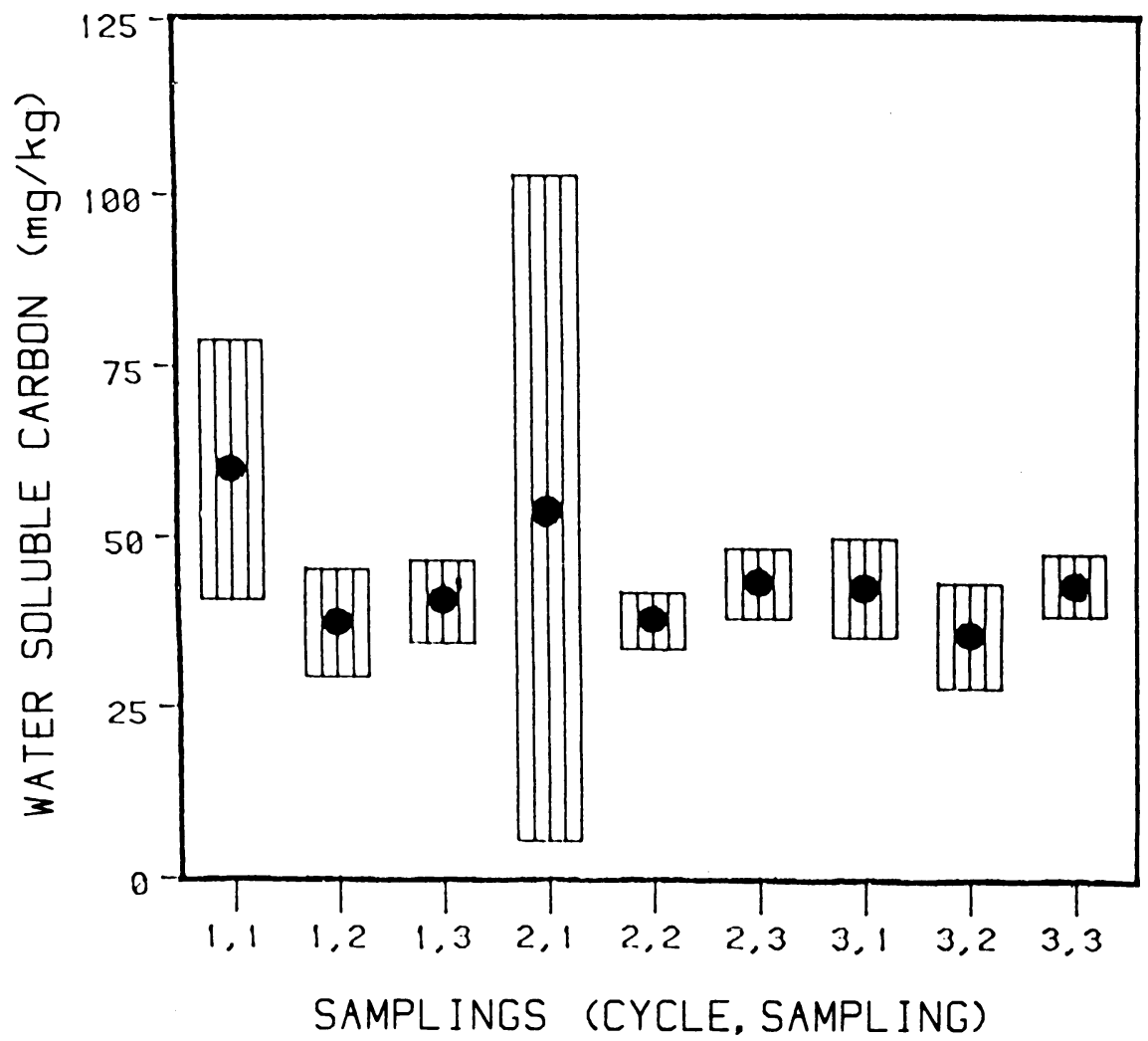

Fig. 8. Means and \pm one standard deviation of WSC from the 0 - to $0.3-\mathrm{m}$ depth for three irrigation cycles. Each mean was determined from at least 12 samples. 
than $66 \%$. Leaching below the $0.3-\mathrm{m}$ sampling depth is one explanation for the rapid decrease in WSC as a result of irrigation. Focht, Stolzy, and Meek (1979) demonstrated leaching of WSC, but under conditions of large additions of manure. It is unlikely that biological activity could account for the large carbon losses over the short period of an irrigation.

\section{SUMMARY AND CONCLUSIONS}

This study directly confirmed that air-drying significantly alters the water-soluble organic carbon extracted from a field sample. In contrast, freezing gave results in excellent agreement with those from fresh samples. Therefore, 200 samples from a 1.2ha field were frozen and later thawed, extracted, and analyzed for soluble organic carbon.

It was found that a ln-normal distribution described the field data better than a normal distribution. The overall distribution is an important parameter to assess. Since the preponderance of values are clustered around the mean of a normal distribution, a high value might be considered as unrepresentative or as an outlier, or it might even be rejected as experimental error. In fact, the higher values may be an integral part of the population and could be expected under similar circumstances. The samples were found to have no spatial dependence for sampling locations of $8.2 \mathrm{~m}$ or greater.

In Burford and Bremner's (1975) work, the water-soluble organic carbon on the 17 soils presented ranged from 9 to $259 \mathrm{mg} / \mathrm{kg}$. Yolo loam is considered a very homogeneous soil, yet the water-soluble carbon from 200 samples taken over 1.2 ha on one day ranged from 23 to $274 \mathrm{mg} / \mathrm{kg}$, encompassing all the values from the Burford and Bremner work except the very lowest of $9 \mathrm{mg} / \mathrm{kg}$. Clearly, if WSC is to be used as an indicator of a field's capacity to denitrify or capability for other reactions, a large number of samples will be required to adequately characterize the mean.

The changes in the mean, the variance, and the distribution of water-soluble organic carbon (WSC) were studied over approximately one year on a 60-point grid of a $0.4-$ ha, unamended field and on a 55-point transect of a manure-amended field. The results indicated that WSC is a dynamic parameter, which, at the very least, changes on a seasonal basis. Although the means were different, the pattern of change in the manure-amended field reflected that in the unamended field. In both cases, the means were highest in the spring and lowest in the summer, while the variances in the summer were generally low. The fall samplings had large variances and were best characterized by a ln-normal distribution. Transforming the data to the ln-normal distribution improved the characterization of the distribution for the spring and summer samplings; nevertheless, normal distribution was quite adequate.

The analysis of spatial dependence of WSC samples from transects indicated only slight dependence at the $1.37-\mathrm{m}$ spacing. By assuming random distribution, a comparison between the means of the amended versus the unamended fields revealed that the fall addition of $45 \mathrm{Mg} / \mathrm{ha}$ of manure significantly affected the level of WSC only until the following fall.

Thus, it is clear from these data for Yolo soil that, if WSC is to be used as a fieldmeasured parameter to assess the energy available to the soil microbial population, the measurement must at least be conducted on a seasonal basis. Furthermore, it must be recognized that, along with the change in the mean, there is a corresponding seasonal change in the variance as well as the frequency distribution.

The results for changes in WSC in the surface soil during irrigation demonstrate that the changes are closely linked to the degree and duration of drying of the upper 0.05 $\mathrm{m}$ of soil before extraction. Irrigation substantially decreases WSC in the surface soil. As the soil dries between irrigations, a steady increase in WSC occurs. 


\section{ACKNOWLEDGMENTS}

The authors acknowledge Dr. O. A. Folorunso, University of Maiduguri, Nigeria, for assistance with some of the data collection and Dr. T. B. Parkin, U.S. Department of Agriculture-Agricultural Research Service, Beltsville, Maryland, for providing the computer program for the Sichel analysis. This research was funded by the California Agricultural Experiment Station.

\section{LITERATURE CITED}

Biggar, J. W., and D. R. Nielsen

1976. Spatial variability of the leaching characteristics of a field soil. Water Resour. Res. 12:78-84.

Birch, H. F.

1958. The effect of soil drying on humus decomposition and nitrogen availability. Plant \& Soil 10:9-32.

1959. Further observations on humus decomposition and nitrification. Plant \& Soil $11: 262-87$.

Birch, H. F., and M. T. Friend

1956. Humus decomposition in East African soils. Nature 178:500-501.

Burford, J. R., and J. M. Bremner

1975. Relationship between the denitrification capacities of soils and total, watersoluble and readily decomposable organic matter. Soil Biol. Biochem. 7:38794.

Davis, J. C.

1973. Statistics and data analysis in geology. New York: John Wiley \& Sons.

Focht, D. D., L. H. Stolzy, and B. O. Meek

1979. Sequential reduction of nitrate and nitrous oxide under field conditions as brought about by organic amendments and irrigation management. Soil Biol. Biochem. 11:37-46.

Hald, A.

1952. Statistical theory with engineering application. New York: John Wiley \& Sons. Jager, G., and E. H. Bruins

1975. Effect of repeated drying at different temperatures on soil organic matter decomposition and characteristics, and on soil microflora. Soil Biol. Biochem. 7:153-59.

Krige, D. G., and E. J. Magri

1982. Studies of the effects of outliers and data transformation on variogram estimates for a base metal and a gold ore body. J. Int. Assoc. Math. Geol. 14:55764.

Lebedjantzev, A. N

1924. Drying of soil as one of the natural factors in maintaining soil fertility. Soil Sci. 18:419-47.

Martin, J. K.

1971. ${ }^{14} \mathrm{C}$ labelled material leached from the rhizosphere of plants supplied with ${ }^{14} \mathrm{CO}_{2}$. Aust. J. Biol. Sci. 24:1131-42.

Meek, B. D., A. J. MacKenzie, T. J. Donovan, and W. F. Spencer

1974. The effect of large applications of manure on movement of nitrate and carbon in an irrigated desert soil. J. Env. Qual. 3:253-58. 
Murayama, S., and A. Moko

1975. Untersuchungen uber den einfluss einer langjahrigen kalkdungung auf die humuszussammensetzung und den kohlenhydratgehalt in reisboden. Soil Science and Plant Nutrition 21:239-51.

Parkin, T. B.

1987. Soil microsites as a source of denitrification variability. Soil Sci. Soc. Am. J. 51: 1194-99.

Patten, D. K., J. M. Bremner, and A. M. Blackmer

1980. Effects of drying and air-drying storage of soils on their capacity for denitrification of nitrate. Soil Sci. Soc. Am. J. 44:67-70.

Reddy, K. R., R. Khaleel, and M. R. Overcash

1980. Carbon transformations in land areas receiving wastes in relation to nonpoint source pollution: A conceptual model. J. Env. Qual. 9:434-42.

Rovira, A. D., and C. B. Davey

1974. Biology of the rhizosphere. pp. 153-205. In The plant root and its environment. E.W. Carson (ed.) Charlottesville: University Press of Virginia.

Sichel, H. S.

1966. The estimation of means and associated confidence limits for small samples from lognormal populations. J. South African Inst. Mining and Metallurgy 67:106-23.

Stanford, G., R. A. VanderPol, and S. Dzienia

1975. Denitrification rates in relation to total and extractable soil carbon. Soil Sci. Amer. Proc. 39:284-89.

Steel, R. G. D., and J. H. Torrie

1980. Principles and procedures of statistics. New York: McGraw-Hill Book Co. Stevenson, F. J.

1982. Humus chemistry: Genesis, composition, reactions. New York: John Wiley and Sons.

Stevenson, F. J., and M. S. Ardakani

1972. Organic matter reactions involving micronutrients in soils. pp. 79-110. In Micronutrients in Agriculture. J. J. Mortvedt, P. M. Giodano, and W.

Stevenson, I. L. L. Lindsay (eds.). Madison, WI: Soil Science Society of America.

1956. Some observations on the microbial activity in remoistened air dried soils. Plant and Soil 8:170-82.

Tukey, J. W.

1977. Exploratory data analysis. Reading, MA: Addison-Wesley Publishing Co.

Vieira, S. R., D. R. Nielsen, and J. W. Biggar

1981. Spatial variability of field-measured infiltration rate. Soil Sci. Soc. Am. J. 45:1040-48.

Warembourg, F. R., and G. Billes

1979. Estimating carbon transfers in the plant rhizospheres. pp. 183-96. In The Soil Root Interface. J. L. Hartley and R. S. Russell (eds.). London: Academic Press.

Winer, B. J.

1971. Statistical principles in experimental design. New York: McGraw-Hill Book Co. 

to be randomly distributed. The addition of manure to the field resulted in higher WSC concentrations than in the unamended field, but concentrations were nearly equal after a year.

Changes in soluble organic carbon in the field are closely related to the degree and duration of drying of the soil before extraction. These changes occur primarily in the upper $0.05 \mathrm{~m}$ of soil. Irrigation causes a drastic decrease in the soluble organic carbon in the surface soil, most likely because of leaching of soluble carbon.

The University of California, in compliance with the Civil Rights Act of 1964, Title IX of the Education Amendments of 1972, and the Rehabilitation Act of 1973, does not discriminate on the basis of race, creed, religion, color, national origin, sex, or mental or physical handicap in any of its programs or activities, or with respect to any of its employment policies, practices, or procedures. The University of California does not discriminate on the basis of age, ancestry, sexual orientation, marital status, citizenship, medical condition (as defined in section 12926 of the California Government Code), nor because individuals are disabled or Vietnam era veterans. Inquiries regarding this policy may be directed to the Personnel Studies and Affirmative Action Manager, University of California, Division of Agriculture and Natural Resources, 300 Lakeside Drive, Oakland, CA 94612-3560, (415) 987-0095 
Edward S. Sylvester, Chairman, Berkeley

(entomology, insecticides, ecology, environmental toxiocology)

Peter Berck, Associate Editor, Berkeley

(economics, statistics, resource management)

Harry W. Colvin, Associate Editor, Davis

(animal science, physiology, breeding, zoology, genetics)

Donald J. Durzan, Associate Editor, Davis (tree fruit and nut crops)

Walter G. Jennings, Associate Editor, Davis

(food science, nutrition, and chemistry)

John Letey, Associate Editor, Riverside

(soils, plant nutrition, agronomy, agricultural engineering, water)

Irwin P. Ting, Associate Editor, Riverside

(botany, plant physiology, biochemistry)

Richard V. Venne, Managing Editor, Oakland

The Journal HILGARDIA is published irregularly. Number of pages and number of issues vary per annually numbered volume. Address: HILGARDIA, Research Publications, Division of Agriculture and Natural Resources, University of California, 300 Lakeside Drive - 6th Floor, Oakland, CA 94612-3560 